\title{
Decreased expression of $R U N X 3$ is correlated with tumor progression and poor prognosis in patients with esophageal squamous cell carcinoma
}

\author{
HIRONORI SUGIURA, HIDEYUKI ISHIGURO, YOSHIYUKI KUWABARA, \\ MASAHIRO KIMURA, AKIRA MITSUI, YOICHIRO MORI, RYO OGAWA, \\ TAKEYASU KATADA, KOSHIRO HARATA and YOSHITAKA FUJII \\ Nagoya City University Graduate School of Medical Sciences, Oncology, Immunology \\ and Surgery, 1 Kawasumi, Mizuho-cho, Mizuho-ku, Nagoya 467-8601, Japan
}

Received July 30, 2007; Accepted October 24, 2007

\begin{abstract}
Runt-related transcription factor 3 (RUNX3) has been reported to be a candidate tumor suppressor gene in gastric cancer. However, in esophageal cancer, the role of RUNX3 has not been studied. The expression of RUNX3 mRNA was quantified by real-time reverse transcription polymerase chain reaction using Taq Man PCR in 15 esophageal cancer cell lines (TE1-15) and 70 esophageal squamous cell carcinoma (ESCC) specimens and their paired normal esophageal mucosa. The data were analyzed with reference to clinicopathological factors. Using specific primers, methylation of the promoter region of RUNX3 was examined. RUNX3 mRNA expression in ESCC tissue was significantly lower than that in the corresponding normal esophageal mucosa $(3.913 \pm 4.617$ vs. $7.795 \pm 15.361$, $\mathrm{P}=0.0345)$. RUNX3 mRNA expression levels in locally invasive T4 tumors were significantly lower than those in less invasive T1-3 tumors $(\mathrm{P}=0.0454)$. Patients who had low RUNX3 mRNA expression levels had a significantly shorter survival after surgery compared with patients who had high $R U N X 3$ mRNA expression $(\mathrm{P}=0.0299)$. Among the 15 esophageal cancer cell lines studied, one had methylation of the promoter region of $R U N X 3$. Only 4 in 70 ESCC tumors had methylation in this region. In conclusion, $R U N X 3$ expression may be involved in the tumor invasion and poor prognosis of patients with ESCC. The methylation of the RUNX3 promoter region in esophageal cancer is rare. A study on the mechanisms that underlie the reduced expression of RUNX3 in ESCC is warranted.
\end{abstract}

Correspondence to: Dr Hideyuki Ishiguro, Nagoya City University Graduate School of Medical Sciences, Oncology, Immunology and Surgery, 1 Kawasumi, Mizuho-cho, Mizuho-ku, Nagoya 467-8601, Japan

E-mail: h-ishi@med.nagoya-cu.ac.jp

Key words: esophageal cancer, prognosis, runt-related transcription factor 3 , hypermethylation

\section{Introduction}

Esophageal squamous cell carcinoma (ESCC) is one of the most common causes of cancer death in Japan. The prognosis for patients with ESCC is poor, prompting a search for new treatment strategies. Although preoperative chemotherapy and chemoradiation therapy are currently used for patients with advanced ESCC, their results are not satisfactory. Even with early-stage disease, many patients will develop locally recurrent tumors or distant metastases within a short period after surgery.

Recent molecular biological studies have revealed that several genes are involved in the carcinogenesis and/or progression of esophageal carcinoma: e.g. TP53 (1), CDKN2A (2), DEC1 (3), DCC (4) and DLC1 (5). It has been reported that mRNA expression of these genes was correlated with survival. Our previous studies have identified candidate genes that may affect the survival of patients with ESCC; survivin (6), DFF45 (7), PTTG1 (8), PPAR y (9), ERCC3 (10), PABPC1 (11), NDRG1 (12), ACP6 (13) and RNASEN (14).

The $R U N X 3$ gene, a candidate tumor suppressor gene, was cloned and identified as a human runt-domain containing gene in 1994 (15). Its precise function is unknown and its role in ESSC has not been studied. In this study, we investigated the RUNX3 mRNA expression in ESCC and its paired normal esophageal mucosa by real-time RT-PCR. We analyzed the results in reference to the patients' clinicopathological characteristics and the prognosis of the ESCC patients. We searched for methylation of the promoter region of RUNX3 in ESCC tissue and cell lines.

\section{Materials and methods}

Cell lines and cell culture. Esophageal cancer cell lines (TE1-15) were obtained from the Japanese Collection of Research Bioresources (JCRB). Cultures were maintained in RPMI-1640 (Sigma) medium supplemented with 10\% fetal bovine serum (FBS) (Gibco) at $37^{\circ} \mathrm{C}$ in a humidified $5 \% \mathrm{CO}_{2}$ incubator.

Tissue samples. Samples were obtained from 70 patients with primary ESCC who had undergone radical esophagectomy at 
Table I. Correlation of $R U N X 3$ mRNA expression in esophageal cancer with clinicopathological factors, including patient and tumor characteristics.

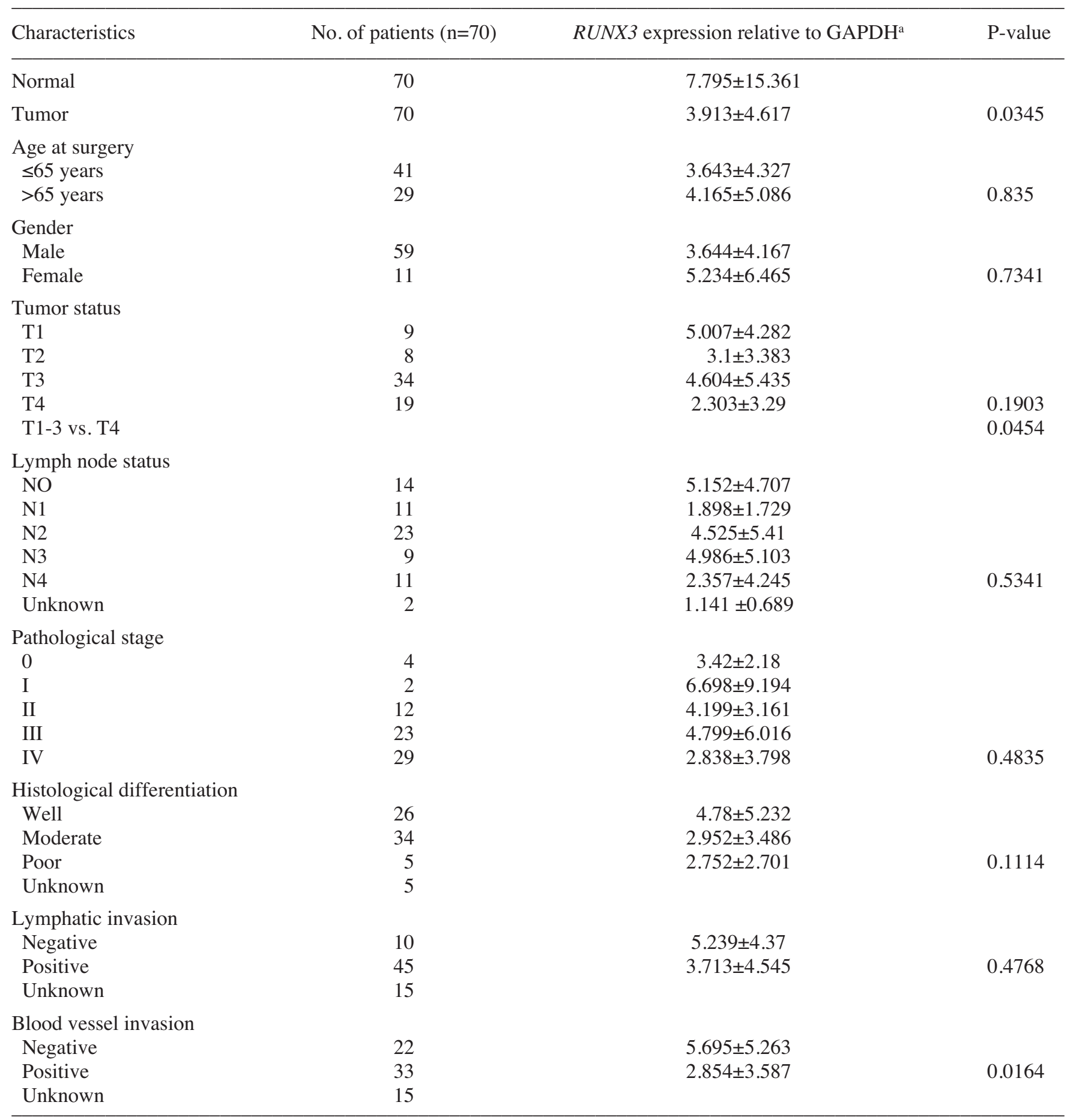

${ }^{a}$ Mean \pm standard deviation (SD). RUNX3, esophageal cancer related gene 4; GAPDH, glyceraldehyde-3-phosphate dehydrogenase.

the Department of Surgery II, Nagoya City University Medical School between 1996 and 2002. The study design was approved by the IRB (Institutional Review Board) of our University hospital, and a written consent was obtained from all the patients. Tumors were classified according to the Guidelines for the Clinical and Pathological Studies on Carcinoma of the Esophagus. Normal esophageal mucosa was taken from the apparently noncancerous mucosa as far apart as possible from the tumor (at least $5 \mathrm{~cm}$ ). All samples were frozen immediately in liquid nitrogen and stored at $-80^{\circ} \mathrm{C}$ until use. The characteristics of the 70 patients with ESCC are shown in Table I.

Nucleic acid isolation and cDNA synthesis. Total RNA was extracted from ESCC tissue and its corresponding normal esophageal mucosa using the Absolutely RNA ${ }^{\mathrm{TM}}$ RT-PCR Miniprep kit (Stratagene, La Jolla, CA) according to the manufacturer's instructions. The concentration of total RNA 


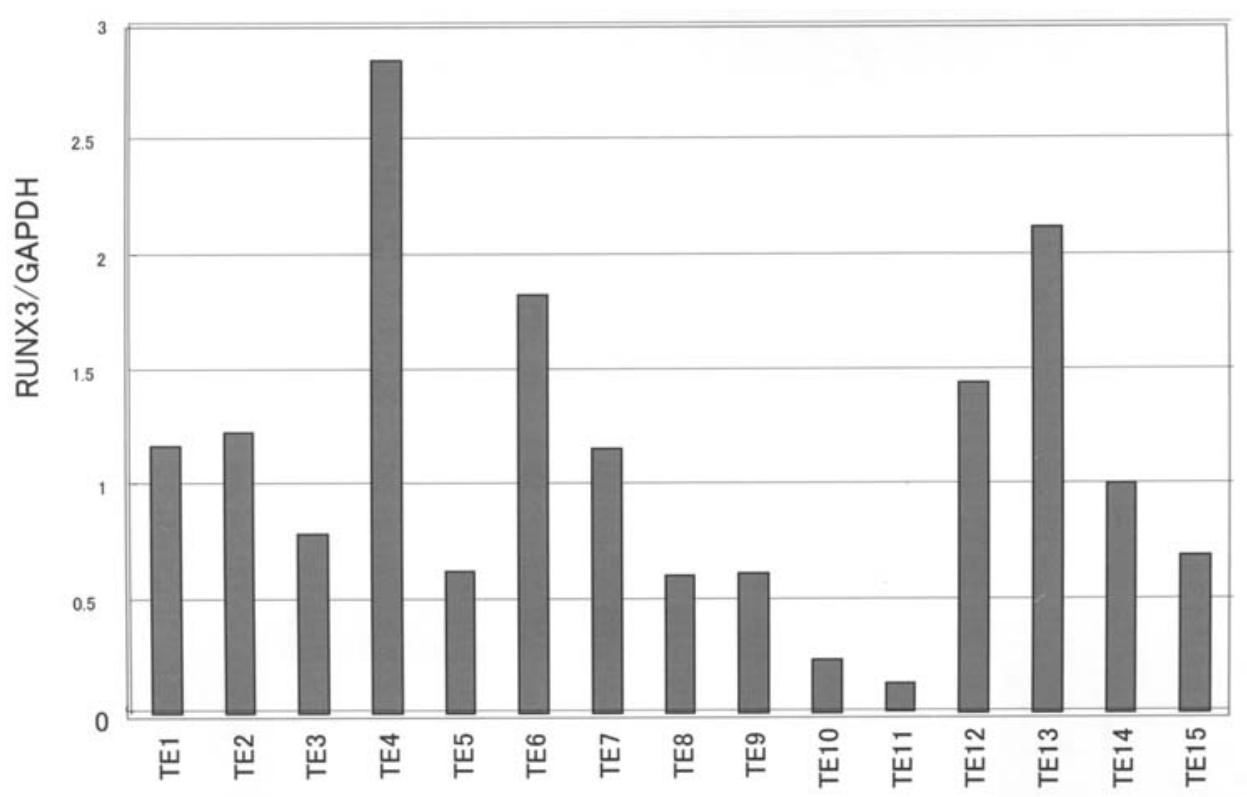

Figure 1. RUNX3/GAPDH mRNA expression levels in esophageal cancer cell lines. TE11 had significantly lower expression than other esophageal cancer cell lines.

was adjusted to $200 \mathrm{ng} / \mathrm{ml}$ using a spectrophotometer. Reverse transcriptase reaction was carried out at $42^{\circ} \mathrm{C}$ for $90 \mathrm{~min}$ and at $95^{\circ} \mathrm{C}$ for $5 \mathrm{~min}$ followed by incubation at $72^{\circ} \mathrm{C}$ for $15 \mathrm{~min}$ using $1 \mu \mathrm{g}$ of total RNA, $0.5 \mu \mathrm{g}$ oligo(dT) primer, and Superscript II enzyme (Gibco BRL, Gaithersburg, MD).

All samples were quantified after PCR amplification using a Lightcycler-Faststart DNA Master SYBR-Green I kit (Roche Molecular Biochemicals, Mannheim, Germany).

Real-time RT-PCR using Taq Man Probes. Real-time quantitative PCR amplification of the cDNA template corresponding to $20 \mathrm{ng}$ total RNA was performed using Taq Man ${ }^{\circledR}$ Universal PCR Master Mix (Applied Biosystems, Foster City, CA, USA) in an ABI PRISM 7500 (Applied Biosystems). PCR conditions were at $50^{\circ} \mathrm{C}$ for $2 \mathrm{~min}$ and at $95^{\circ} \mathrm{C}$ for $10 \mathrm{~min}$, followed by 40 cycles at $95^{\circ} \mathrm{C}$ for $15 \mathrm{sec}$ and $60^{\circ} \mathrm{C}$ for $1 \mathrm{~min}$. $R U N X 3$-specific Taq Man probes were designed from sequences in exons 4 and 5 (Assays-on-Demand Gene Expression system, RUNX3-assay ID:Hs00231709_m1, Applied Biosystems). Expression levels were normalized against glyceraldehyde-3-phosphate dehydrogenase (GAPDH) (Assays-on-Demand Gene Expression system, assay ID Hs99999905_m1, Applied Biosystems).

Genomic DNA and methylation-specific PCR. Genomic DNA and total RNA were isolated from each sample of ESCC and its corresponding normal esophageal mucosa. Genomic DNA was extracted using a standard SDS-proteinase K procedure.

Sodium bisulfite modification of genomic DNA was performed by the CpGenome ${ }^{\mathrm{TM}}$ DNA modification kit (Chemicon International, CA, USA). Methylation-specific PCR was performed using PCR primers which were designed to be specific to either methylated or unmethylated DNA after sodium bisulfite modification described previously. Methylated DNA-specific primers were 5'-TTACGAGG GGCGGTCGTACGCGGG-3' (sense) and 5'-AAAACG ACCGACGCGAACGCCTCC-3' (antisense). Unmethylated
DNA-specific primers were 5'-TTATGAGGGGTGGTTG TATGTGGG-3' (sense) and 5'-AAAACAACCAACACA AACACCTCC-3' (antisense).

Statistical analysis. Data are expressed as mean \pm standard deviation (SD). Statistical analysis was performed using the Stat-View software package (Abacus Concepts, Berkeley, CA). The Wilcoxon signed-ranks test, Mann-Whitney U test, and Kruskal-Wallis test were used to evaluate the significance of differences in expression levels of RUNX3/GAPDH mRNA. Statistical analyses were carried out using Stat-View software (Abacus Concepts). The survival of ESCC patients after surgery was examined using the Kaplan-Meier method and survival times were compared using the log-rank test. Multivariate analysis was performed using Cox's regression model and the logistic multivariate regression model. P-values were considered significant at the $\mathrm{P}<0.05$ level.

\section{Results}

Expression of RUNX3 in esophageal cancer cell lines. We examined the expression of $R U N X 3$ mRNA in 15 esophageal cancer cell lines (TE1 to TE15) using quantative RT-PCR. Expression of RUNX3 and GAPDH mRNA was detectable in all esophageal cancer cell lines. TE11 had the lowest expression and TE4 had the highest expression of RUNX3 among the cell lines studied (Fig. 1).

Expression of RUNX3 in esophageal cancer tissues. RUNX3 mRNA expression was detectable in all ESCC tissue and noncancerous esophageal mucosa. It was standardized using the expression of GAPDH. The levels of expression of RUNX3 mRNA in ESCC tissue were significantly lower than those in the corresponding normal esophageal mucosa $(3.913 \pm 4.617$ vs. 7.795 $\pm 15.361, \mathrm{P}=0.0345$; Wilcoxon signed-rank test) (Table I). We examined the relationship between RUNX3/ $G A P D H$ mRNA expression in 70 ESCC samples and the 


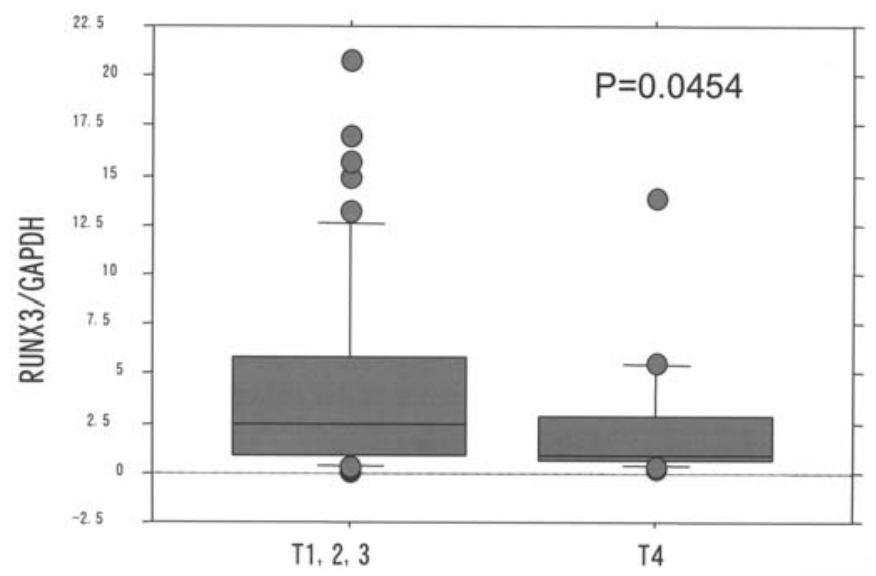

Figure 2. RUNX3/GAPDH mRNA expression levels in patients with locally invasive T4 tumors were significantly lower than those in less invasive T1-3 tumors ( $\mathrm{P}=0.0454$; Mann-Whitney $\mathrm{U}$ test).

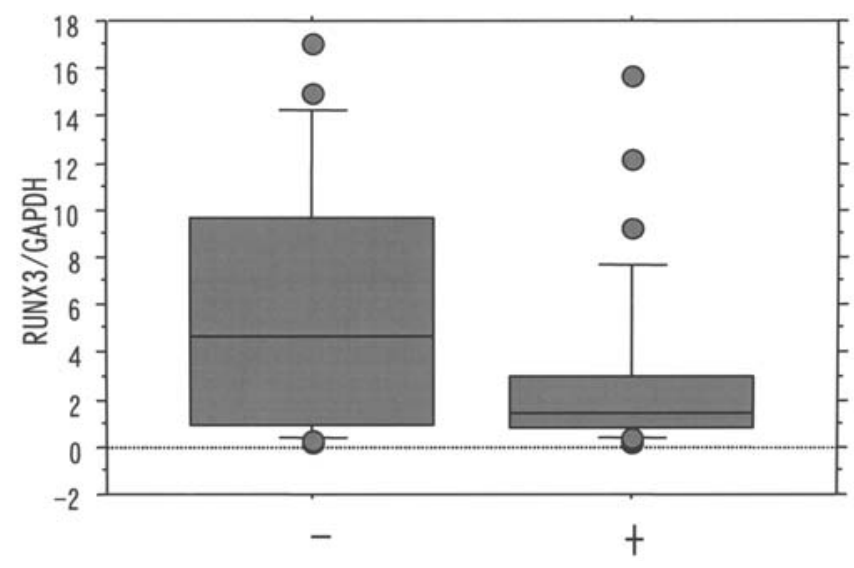

Figure 3. RUNX3/GAPDH mRNA expression levels in blood vessel invasion positive ESCC tissue were significantly lower than those of negative ESCC tissues ( $\mathrm{P}=0.0164$; Mann-Whitney $\mathrm{U}$ test).

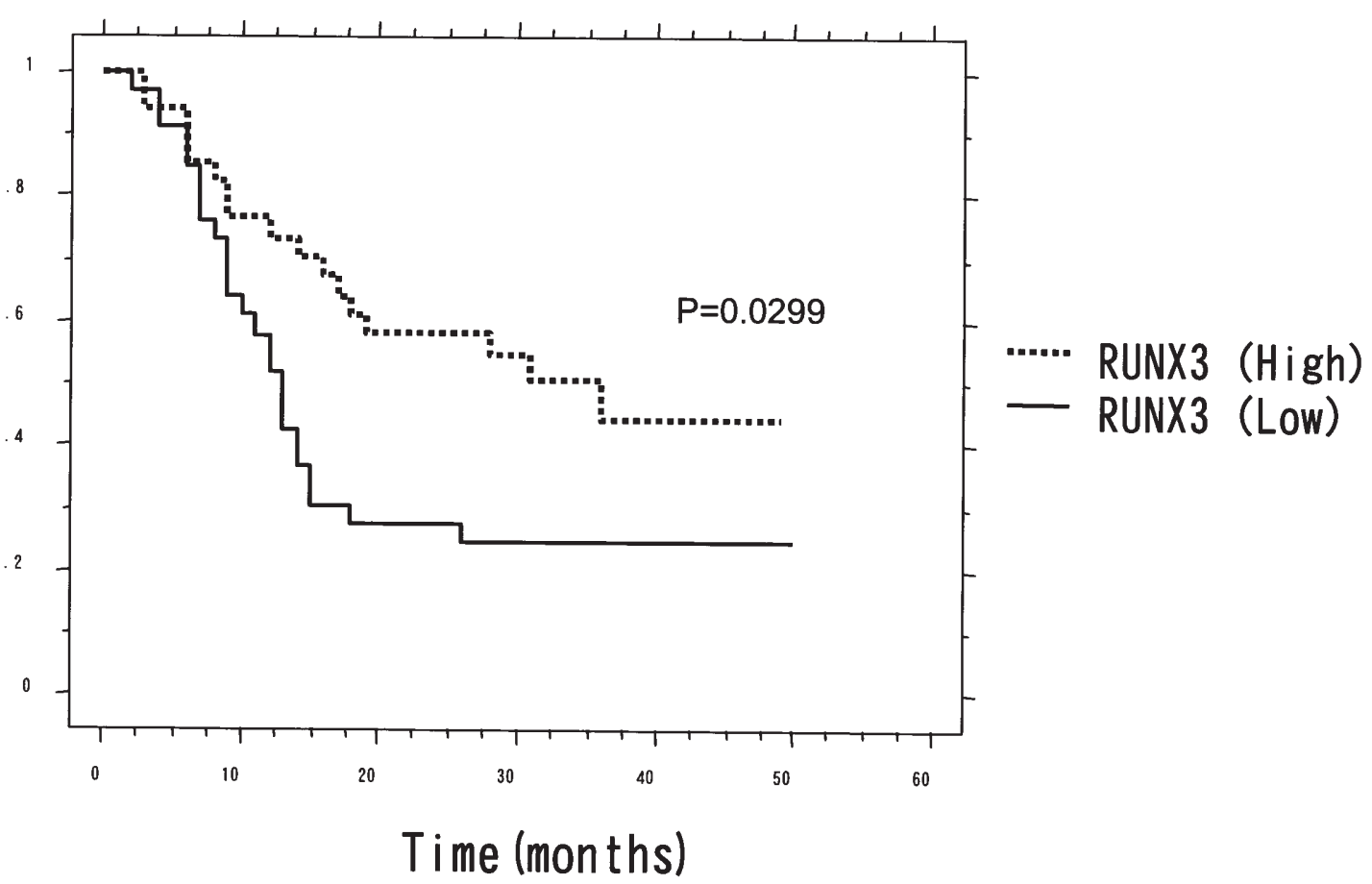

Figure 4. Patients who had low $R U N X 3 / G A P D H$ mRNA expression levels $(R U N X 3 / G A P D H$ mRNA expression in the tumor <2.0; $\mathrm{n}=36)$ had a significantly shorter survival (14.3 \pm 1.4 months) after surgery compared with patients who had high $R U N X 3$ mRNA expression levels $(R U N X 3 / G A P D H>2.0$, n=34; $28.3 \pm 2.6$ months $)(\mathrm{P}=0.0299$, log-rank test $)$.

patients' clinicopathological factors (Table I). Of the 70 ESCC samples studied, there were no significant differences in $R U N X 3 / G A P D H$ mRNA according to age, gender, lymph node status, histological differentiation and lymphatic invasion. RUNX3/GAPDH mRNA expression levels in patients with locally invasive $\mathrm{T} 4$ tumors were significantly lower than those in less invasive T1-3 tumors $(\mathrm{P}=0.0454$; Mann-Whitney U test) (Table I, Fig. 2). RUNX3/GAPDH mRNA expression levels in tumors with blood vessel invasion were significantly lower than those in vessel invasion negative tumors ( $\mathrm{P}=0.0164$; Mann-Whitney U test) (Table I, Fig. 3).

We investigated the correlation between the RUNX3/ GAPDH mRNA expression levels and the survival of ESCC patients after surgery (median follow-up, 24.8 months).
Patients who had low $R U N X 3 / G A P D H$ mRNA expression levels (indicated as the ratio of $R U N X 3 / G A P D H<2.0, \mathrm{n}=34$ ) had a significantly shorter survival (14.3 \pm 1.4 months) after surgery compared with patients who had high $R U N X 3 / G A P D H$ mRNA expression levels (RUNX3/GAPDH mRNA > 2.0, $\mathrm{n}=36 ; 28.3 \pm 2.6$ months $)(\mathrm{P}=0.0299, \log$-rank test $)$ (Fig. 4). Univariate analysis showed that among the clinicopathological factors, the local invasiness (tumor status) (risk ratio 4.716; $\mathrm{P}<0.0001$ ), lymph node metastasis (node status) (risk ratio 32.849; $\mathrm{P}=0.0019$ ), lymphatic invasion (risk ratio 10.526; $\mathrm{P}=0.0012$ ), blood vessel invasion (risk ratio 3.27; $\mathrm{P}=0.0005$ ) and RUNX3 expression $(<2.0)$ (risk ratio 1.908; $\mathrm{P}=0.0355$ ) were statistically significant prognostic factors (Table II). However, multivariate analysis revealed that RUNX3 
Table II. Univariate analysis.

\begin{tabular}{|c|c|c|c|}
\hline Parameter & Risk ratio & $95 \% \mathrm{Cl}$ & P-value \\
\hline \multicolumn{4}{|c|}{ Age at surgery } \\
\hline$>65$ years & 1 & & \\
\hline$\leq 65$ years & 1.083 & $0.660-1.776$ & 0.7523 \\
\hline \multicolumn{4}{|l|}{ Gender } \\
\hline Female & 1 & & \\
\hline Male & 1.220 & $0.65-2.30$ & 0.5225 \\
\hline \multicolumn{4}{|c|}{ Tumor status } \\
\hline $\mathrm{T} 1-3$ & 1 & & \\
\hline $\mathrm{T} 4$ & 4.716 & $2.710-8.196$ & 0.0001 \\
\hline \multicolumn{4}{|c|}{ Lymph node status } \\
\hline NO-3 & 1 & & \\
\hline N4 & 2.849 & $1.472-5.494$ & 0.0019 \\
\hline \multicolumn{4}{|c|}{ Lymphatic invasion } \\
\hline Negative & 1 & & \\
\hline Positive & 10.526 & $2.551-43.472$ & 0.0012 \\
\hline \multicolumn{4}{|c|}{ Blood vessel invasion } \\
\hline Negative & 1 & & \\
\hline Positive & 3.270 & $1.672-6.410$ & 0.0005 \\
\hline \multicolumn{4}{|c|}{$R U N X 3$ expression } \\
\hline High & 1 & & \\
\hline Low & 1.908 & $1.044-3.484$ & 0.0355 \\
\hline
\end{tabular}

$\mathrm{Cl}$, confidence interval.

(A)

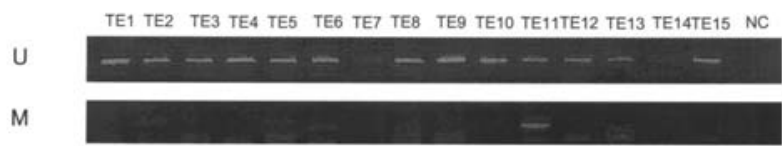

(B)

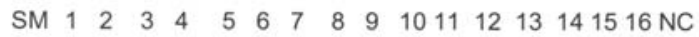

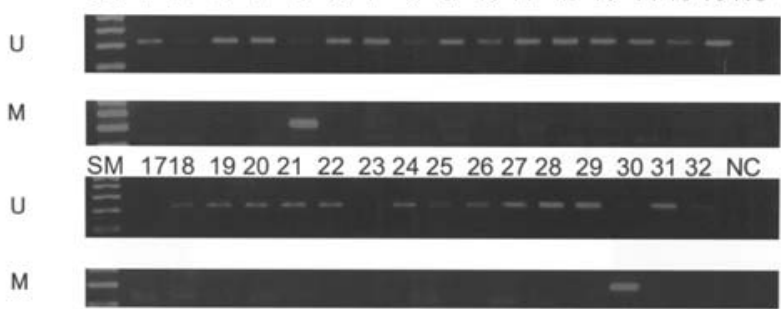

Figure 5. (A) Analysis of 15 esophageal cancer cell lines using MSP. M, methylated sequence-specific PCR; U, unmethylated sequence-specific PCR; SM, size marker. (B) Analysis of esophageal cancer tissues after surgery using MSP. Representative 32 cases are shown. Patients \#5 (upper panel) and \#30 have methylation in the promoter region of RUNX3. M, methylated sequence-specific PCR; U, unmethylated sequence-specific PCR; SM, size marker; NC, negative control.

expression $(R U N X 3 / G A P D H<2.0)$ was not an independent prognostic factor (data not shown).

Methylation PCR of RUNX3 CpG islands. Methylation-specific PCR was performed in order to analyze the methylation status of $R U N X 3 \mathrm{CpG}$ islands in the esophageal cancer cell lines.
Genomic DNA extracted from 15 esophageal cancer cell lines, TE1-15, were treated with sodium bisulfite. Methylationspecific PCR was performed using PCR primers which were designed to be specific to either methylated or unmethylated DNA after sodium bisulfite modification. Among the 15 cell lines, methylation was detected only in TE11.

We then analyzed the methylation status of RUNX3 CpG islands in 70 primary ESCC samples and their paired normal esophageal tissues using the MSP technique. Among the 70 primary ESCC samples, only four samples were found to have $R U N X 3$ promoter methylation (Fig. 5). In any of the normal esophageal mucosa, methylation of RUNX3 was not observed (data not shown).

\section{Discussion}

In this study, we examined $R U N X 3$ expression in 70 cases of ESCC at the mRNA level by quantitative RT-PCR. The $R U N X 3$ gene was expressed abundantly in noncancerous esophageal epithelium, though it was down-regulated in ESCC tissue. Among the clinicopathological factors examined, we observed a significant correlation between RUNX3 expression and the depth of invasion ( $\mathrm{T}$ factor), vascular invasion and survival of patients with ESCC. These results indicate a close association between the RUNX3 expression and the growth and invasion of ESCC.

In search of possible mechanism(s) of the down-regulation of $R U N X 3$, we examined DNA methylation of $\mathrm{CpG}$ islands of $R U N X 3$ promotor region. We found that the hypermethylation 
in $R U N X 3$ promotor region is rare (only $4 / 70,5.7 \%$ of all the patients). Other possible mechanisms that downregulate RUNX3, including mutation and loss of heterozygosity (LOH), was not examined in this study. This gene is located at chromosome $1 \mathrm{p} 36$, where frequent $\mathrm{LOH}$ has been reported in human malignancies, such as neuroblastoma (16), oral and laryngeal squamous carcinoma (17), lung carcinoma (18) and prostate carcinoma (19). $\mathrm{LOH}$ in $1 \mathrm{p} 36$ has been detected in esophageal cancer patients and within this region, it was suggested to harbor a putative tumor suppressor gene (20).

Many tumor suppressor genes are downregulated by promoter methylation during the development and progression of cancer, and hypermethylation of gene-promoter regions is being revealed as one of the most frequent mechanisms in the loss of gene function, thus detection of $\mathrm{CpG}$ methylation is important in understanding the gene regulation of cancer. It has been reported that the expression of some tumor suppressor genes, such as p15INK4b, p16INK4a, FHIT and E-cadherin are commonly down-regulated by $\mathrm{CpG}$ island hypermethylation in ESCC $(10,21,22)$. Aberrant methylation of $\mathrm{CpG}$ islands in the core promoter of the RUNX3 gene was reported to be a frequent molecular event in gastric cancer (23-25), lung cancer (26) and bladder tumor (27). These results indicate that the inactivation of the RUNX3 gene by hypermethylation in gastric cancer may be involved in the carcinogenesis of the cancer. However, in our study, the hypermethylation of the $R U N X 3$ promoter region was a rare event. In addition to epigenetic change including methylation, silencing due to LOH or mutation may be responsible for the downregulation of $R U N X 3$. This possibility remains to be examined.

RUNX3 is a downstream target of the TGF- $\beta$ signaling pathway. Hanai et al reported that RUNX3 interacts with Smads which transduce TGF- $\beta$ signals (28). The downregulation of SMAD4 in esophageal cancers is correlated with poor prognosis (29). Furthermore, RUNX3 is a transcription factor that regulates numerous downstream genes, for example, the cell-cycle regulator p21 (30). Thus, RUNX3 is a candidate tumor suppressor.

Although the precise molecular mechanism of the downregulation of RUNX3 expression needs to be clarified, our data indicate that $R U N X 3$ may be involved in prognosis and tumor invasion in patients with ESCC. The locally invasive T4 ESCCs are not candidates for surgery. In view of the reduced expression of RUNX3 in T4 ESCC and in ESCC with poor prognosis, $R U N X$ may be the target of future therapy in this intractable disease.

\section{Acknowledgements}

The authors would like to thank Ms. Shinobu Makino for her excellent technical assistance.

\section{References}

1. Robert V, Michel P, Flaman JM, et al: High frequency in esophageal cancers of p53 alterations inactivating the regulation of genes involved in cell cycle and apoptosis. Carcinogenesis 21: $563-565,2000$.

2. Suzuki H, Zhou X, Yin J, et al: Intragenic mutations of CDKN2B and CDKN2A in primary human esophageal cancers. Hum Mol Genet 4: 1883-1887, 1995.
3. Nishiwaki T, Daigo Y, Kawasoe T and Nakamura Y: Isolation and mutational analysis of a novel human cDNA, DEC1 (deleted in esophageal cancer 1), derived from the tumor suppressor locus in 9q32. Genes Chromosomes Cancer 27: 169-176, 2000.

4. Miyake S, Nagai K, Yoshino K, Oto M, Endo M and Yuasa Y: Point mutations and allelic deletion of tumor suppressor gene DCC in human esophageal squamous cell carcinomas and their relation to metastasis. Cancer Res 54: 3007-3010, 1994.

5. Daigo Y, Nishiwaki T, Kawasoe T, Tamari M, Tsuchiya E and Nakamura Y: Molecular cloning of a candidate tumor suppressor gene, DLC1, from chromosome 3p21.3. Cancer Res 59: 1966-1972, 1999.

6. Kato J, Kuwabara Y, Mitani M, et al: Expression of survivin in esophageal cancer: correlation with the prognosis and response to chemotherapy. Int J Cancer 95: 92-95, 2001.

7. Konishi S, Ishiguro H, Shibata Y, et al: Decreased expression of DFF45/ICAD is correlated with a poor prognosis in patients with esophageal carcinoma. Cancer 95: 2473-2478, 2002.

8. Shibata Y, Haruki N, Kuwabara Y, et al: Expression of PTTG (pituitary tumor transforming gene) in esophageal cancer. Jpn J Clin Oncol 32: 233-237, 2002.

9. Terashita Y, Sasaki H, Haruki N, et al: Decreased peroxisome proliferator-activated receptor gamma gene expression is correlated with poor prognosis in patients with esophageal cancer. Jpn J Clin Oncol 32: 238-243, 2002.

10. Terashita $\mathrm{Y}$, Ishiguro $\mathrm{H}$, Haruki $\mathrm{N}$, et al: Excision repair cross complementing 3 expression is involved in patient prognosis and tumor progression in esophageal cancer. Oncol Rep 12: 827-831, 2004.

11. Takashima N, Ishiguro H, Kuwabara Y, et al: Expression and prognostic roles of PABPC1 in esophageal cancer: correlation with tumor progression and postoperative survival. Oncol Rep 15: 667-671, 2006.

12. Ando T, Ishiguro H, Kimura M, et al: Decreased expression of NDRG1 is correlated with tumor progression and poor prognosis in patients with esophageal squamous cell carcinoma. Dis Esophagus 19: 454-458, 2006.

13. Ando T, Ishiguro H, Kuwabara Y, et al: Expression of ACP6 is an independent prognostic factor for poor survival in patients with esophageal squamous cell carcinoma. Oncol Rep 15: 1551-1555, 2006.

14. Sugito N, Ishiguro H, Kuwabara Y, et al: RNASEN regulates cell proliferation and affects survival in esophageal cancer patients. Clin Cancer Res 12: 7322-7328, 2006.

15. Levanon D, Negreanu V, Bernstein Y, Bar-Am I, Avivi L and Groner Y: AML1, AML2, and AML3, the human members of the runt domain gene-family: cDNA structure, expression, and chromosomal localization. Genomics 23: 425-432, 1994.

16. Abel F, Sjoberg RM, Ejeskar K, Krona C and Martinsson T: Analyses of apoptotic regulators CASP9 and DFFA at 1P36.2, reveal rare allele variants in human neuroblastoma tumours. Br J Cancer 86: 596-604, 2002.

17. El-Naggar AK, Lai S, Clayman GL, et al: p73 gene alterations and expression in primary oral and laryngeal squamous carcinomas. Carcinogenesis 22: 729-735, 2001

18. Nomoto S, Haruki N, Tatematsu Y, Konishi H, Mitsudomi T, and Takahashi T: Frequent allelic imbalance suggests involvement of a tumor suppressor gene at $1 \mathrm{p} 36$ in the pathogenesis of human lung cancers. Genes Chromosomes Cancer 28: 342-346, 2000.

19. Badzioch M, Eeles R, Leblanc G, et al: Suggestive evidence for a site specific prostate cancer gene on chromosome $1 \mathrm{p} 36$. The CRC/BPG UK Familial Prostate Cancer Study Coordinators and Collaborators. The EU Biomed Collaborators. J Med Genet 37: 947-949, 2000.

20. Nimura Y, Mihara M, Ichimiya S, et al: p73, a gene related to $\mathrm{p} 53$, is not mutated in esophageal carcinomas. Int J Cancer 78 : 437-440, 1998.

21. Xing EP, Nie Y, Song Y, Yang GY, Cai YC, Wang LD and Yang CS: Mechanisms of inactivation of p14ARF, p15INK4b, and p16INK4a genes in human esophageal squamous cell carcinoma. Clin Cancer Res 5: 2704-2713, 1999.

22. Si HX, Tsao SW, Lam KY, et al: E-cadherin expression is commonly downregulated by $\mathrm{CpG}$ island hypermethylation in esophageal carcinoma cells. Cancer Lett 173: 71-78, 2001.

23. Homma N, Tamura G, Honda T, Matsumoto Y, Nishizuka S, Kawata $S$ and Motoyama T: Spreading of methylation within RUNX3 CpG island in gastric cancer. Cancer Sci 97: 51-56, 2006.

24. So K, Tamura G, Honda T, et al: Quantitative assessment of RUNX3 methylation in neoplastic and non-neoplastic gastric epithelia using a DNA microarray. Pathol Int 56: 571-575, 2006. 
25. Usui T, Aoyagi K, Saeki N, et al: Expression status of RUNX1/AML1 in normal gastric epithelium and its mutational analysis in microdissected gastric cancer cells. Int J Oncol 29: 779-784, 2006.

26. Yanada M, Yaoi T, Shimada J, et al: Frequent hemizygous deletion at 1p36 and hypermethylation downregulate RUNX3 expression in human lung cancer cell lines. Oncol Rep 14: 817-822, 2005

27. Kim WJ, Kim EJ, Jeong P, et al: RUNX3 inactivation by point mutations and aberrant DNA methylation in bladder tumors. Cancer Res 65: 9347-9354, 2005.
28. Hanai J, Chen LF, Kanno T, et al: Interaction and functional cooperation of PEBP2/CBF with Smads. Synergistic induction of the immunoglobulin germline Calpha promoter. J Biol Chem 274: 31577-31582, 1999.

29. Natsugoe S, Xiangming C, Matsumoto M, et al: Smad4 and transforming growth factor beta1 expression in patients with squamous cell carcinoma of the esophagus. Clin Cancer Res 8: $1838-1842,2002$

30. Chi XZ, Yang JO, Lee KY, et al: RUNX3 suppresses gastric epithelial cell growth by inducing p21(WAF1/Cip1) expression in cooperation with transforming growth factor $\{$ beta\}-activated SMAD. Mol Cell Biol 25: 8097-8107, 2005. 